\title{
Assessment of upper limb in tetraplegia: Considerations in evaluation and outcomes research
}

\author{
MJ Mulcahey, PhD, OTR/L;* Dave Hutchinson, MS, PT; Scott Kozin, MD \\ Shriners Hospitals for Children, Philadelphia, PA
}

\begin{abstract}
This article briefly discusses several measurement tools for evaluating the upper limb of persons with tetraplegia. Muscle strength testing and electrodiagnostics are discussed as they relate to technique and usefulness for clinical trials. Standardized measures of hand function are reviewed; their limitations for clinical trials during acute spinal cord injury (SCI) care are acknowledged and their strengths for interventional studies and clinical trials during chronic phases of SCI care are defined. Recommendations are set forth for incorporating the International Classification for Surgery of the Hand in Tetraplegia motor and sensory examinations as adjuncts to the International Standards for Neurological Classification of SCI motor and sensory examinations and for further developing electrodiagnostic techniques as measurement tools for acute clinical trials. The Grasp and Release Test is described and recommended for clinical trials involving persons in the chronic stages of SCI. Lastly, we note that much work remains in the development, validation, and clinical deployment of an assessment of upper-limb function in SCI.
\end{abstract}

Key words: clinical trials, functional electrical stimulation, hand function, ICSHT, muscle strength testing, outcomes measures, rehabilitation, spinal cord injury, tendon transfers, upperlimb evaluation.

\section{INTRODUCTION}

Over the past decade, efforts by participants of the International Conference on Surgical Rehabilitation of the Upper Limb in Tetraplegia have focused on identifying sensitive, reliable, and meaningful outcome measures of upper-limb (UL) function in tetraplegia [1-6]. Most studies on UL improvement have applied either hand assessments designed for populations other than spinal cord injury (SCI) or activities of daily living (ADL) scales that may or may not be sensitive to changes in the hand and arm function of persons with SCI [7]. However, the advancement in functional electrical stimulation (FES) systems and reconstructive surgical procedures and the realities of clinical trials have catalyzed an international focus on measurement issues surrounding UL evaluation in tetraplegia. Stroh-Wuolle et al. [8-9], van Tuijl et al. [10], and Bryden et al. [11] described criteria for an appropriate tool for evaluating UL function in persons with tetraplegia. Collectively, these authors agree that the criteria include (1) activities that are appropriate for persons with tetraplegia and represent their ability to perform actual ADL requiring hand function, (2) insensi-

Abbreviations: $\mathrm{ADL}=$ activities of daily living, $\mathrm{C}=$ cervical, CUE = Capabilities of the Upper Extremity, EMG = electromyography, FES = functional electrical stimulation, GRT = Grasp and Release Test, ICSHT = International Classification for Surgery of the Hand in Tetraplegia, IMSOP = International Medical Society of Paraplegia, ISCSCI = International Standards for Neurological Classification of Spinal Cord Injury, LMN = lower motor neuron, $\mathrm{NCV}=$ nerve conduction velocity, $\mathrm{SCI}=$ spinal cord injury, $\mathrm{SD}=$ strength-duration, $\mathrm{T}=$ thoracic, $\mathrm{THAQ}=$ Tetraplegia Hand Activity Questionnaire, UL = upper limb.

* Address all correspondence to MJ Mulcahey, PhD, OTR/L; Shriners Hospitals for Children, Philadelphia Hospital, 3551 North Broad Street, Philadelphia, PA 19140; 215-4304081; fax: 215-430-4123. Email: mmulcahey@shrinenet.org DOI: 10.1682/JRRD.2005.10.0167 
tivity to learning, (3) standardized administration, (4) an unambiguous scale that does not combine too many aspects of function (e.g., concurrent scoring of level of independence and time for completion), (5) multiple trials for helping ensure reliability, and (6) sensitivity to small but clinically significant changes provided by recovery, treatment, or intervention for restoring UL function.

This article reviews assessments commonly used for measuring hand and arm function in persons with SCI. ADL measures, while commonly used as indirect measures of arm and hand function, are beyond the scope of this article but have been well-described elsewhere [1021]. The role of electrophysiological evaluation is described and emerging UL evaluative technologies are introduced. Finally, the strengths and limitations of select assessments for use in clinical trials are described.

\section{ASSESSMENT OF MUSCLE STRENGTH AND SENSATION}

\section{International Standards for Neurological Classification of Spinal Cord Injury}

The American Spinal Injury Association first published a standard system for neurological assessment and classification of SCI in 1982 [22]. Following a decade of use, major revisions to the system were published [23] and adopted by the International Medical Society of Paraplegia (IMSOP) (now the International Spinal Cord Society). Adoption by IMSOP reflected the international SCI community's acceptance of the system as the standard for neurological assessment of persons with SCI. Most recently, Marino et al. clarified terminology related to the standards [24], and in their current form [25], the standards continue to represent the most widespread method for assessment of neurological consequence and classification of SCI.

The International Standards for Neurological Classification of Spinal Cord Injury (ISCSCI) motor and sensory examinations (exams) have been used for describing adult and pediatric populations with SCI [26-28]. However, unlike other aspects of SCI assessment, the motor and sensory exams have also been the primary indicators of recovery of neurological function [29-33]. For example, Waters et al. studied recovery patterns of motor and sensory functions in adults with paraplegia [34] and tetraplegia [35]. Serial examination of motor and sensory functions with the ISCSCI were performed on 148 persons with paraplegia. Results showed that initial neurological motor level above thoracic level 9 (T9) was associated with poor neurological recovery at follow-up, while initial neurological motor level below T9 was associated with more favorable recovery, particularly in the muscles that straighten the hips and knees. Waters et al. also showed that recovery of sensation at follow-up was not associated with initial sensory scores [34]. Waters et al.'s work with persons with tetraplegia showed a consistent, predictable pattern of motor recovery [35]. For muscles with initial motor scores of grade 1 or 2, strength increased at 1-year follow-up to at least grade 3 . In contrast, for the majority of the muscles with initial motor scores of grade 0 (complete paralysis), strength at followup never exceeded grade 3 . Other researchers have studied the relationship between motor and sensory scores and bladder recovery [36], the recovery patterns of muscle strength and sensation in vascular injuries [37], and the relationship between motor scores and functional recovery [37-41].

The ISCSCI motor and sensory exams have also been used as inclusion criteria for entry into drug and device trials. While Bracken et al.'s work added additional UL muscles and variation in the scoring technique [42], neurological motor level was the primary outcome in their study on high-dose methylprednisolone. Also, in unpublished current clinical trials for acute and chronic SCI, motor and sensory scores and level of SCI completeness as defined by the ISCSCI are used as entry criteria and primary outcomes. Activity-based rehabilitation, a program of intensive cycling, assisted treadmill training, and swimming, also uses the ISCSCI exams as primary outcomes [43]. Studies of FES devices have extensively used ISCSCI motor and sensory criteria as both entry criteria and outcome variables [44-48]. Limitations of the ISCSCI classification for UL assessment have been described $[7,11,49]$; the most notable are that it provides insufficient information on UL muscle function for effective treatment and measurement outcomes, is insensitive to the very small but clinically significant changes in hand and arm strength, and has questionable utility with children and youth.

\section{International Classification for Surgery of the Hand in Tetraplegia}

While the ISCSCI remains the most commonly used motor and sensory assessment in tetraplegia, the International Classification for Surgery of the Hand in Tetraplegia 
(ICSHT), an alternative classification scheme, has been introduced specifically for surgical planning in the UL in tetraplegia [2,7]. Like the ISCSCI, the ICSHT involves both examination of motor and sensory function and classification of neurological status. For the ICSHT motor exam, muscles below the shoulder are evaluated on the same ordinal scale used for the ISCSCI motor exam, except that all UL muscles are evaluated (as opposed to five key muscles with the ISCSCI) and the determining muscle strength for classification is grade 4 (as opposed to grade 3 with the ISCSCI). The ICSHT sensory exam involves testing two-point discrimination on the thumb and index finger; sensation is considered intact if twopoint discrimination is $\leq 10 \mathrm{~mm}$. When two-point discrimination is $>10 \mathrm{~mm}$, persons are considered to only have ocular input for hand function. For example, as shown in the Figure, an individual classified as having a motor C5 injury by the ISCSCI could be classified into one of two motor groups by the ICSHT: group 0 or group 1 . Group 0 specifies that the individual has elbow flexion as a result of biceps function but no redundant elbow flexors available for transfer to another function. Group 1 specifies that, in addition to elbow flexion from the biceps, the individual's brachioradialis muscle strength is a grade 4 and thus available for tendon transfer.

While the ICSHT was designed to aid planning of surgical reconstruction, it may be more sensitive than the ISCSCI, at least for assessment of strength, since it evaluates more key UL muscles.

\begin{tabular}{|l|}
$\begin{array}{c}\text { ICSHT } \\
\text { (Grade 4 MMT) }\end{array}$ \\
ISCSCI \\
(Grade 3 MMT)
\end{tabular}

Figure.

Comparison of International Classification for Surgery of the Hand in Tetraplegia (ICSHT) and International Standards for Neurological Classification of Spinal Cord Injury (ISCSCI). C = cervical, MMT = manual muscle test.
Despite the strengths and international use of the ISCSCI and the ICSHT, both evaluation and classification schemes depend upon manual strength testing, which is an inadequate measure in isolation of other strength measures because of variability in scaling (ordinal scales $0-5$ vs ordinal scales $0-5$ that include “+”), grading of strength, and limb position during testing. For muscles with a strength grade of at least 3 out of 5 , hand-held dynamometry is a useful adjunct to the manual muscle test [50-52]. May and colleagues described a break test in which the tester overcomes the strength of the person being tested and a make test in which the tester holds the dynamometer stable while the person being tested exerts maximum strength [53]. Make and break techniques for hand-held dynamometry show high reliability when used for measuring elbow flexion and extension [54]. The Jamar and Preston and the Penny and Giles instruments have been used with the tetraplegia population $[50,52,55]$. While isokinetic dynamometry is an important measurement, it is challenging with this population because positioning the person so as to eliminate use of compensatory patterns is difficult, particularly when muscles about the shoulder and upper arm are being measured. Thus, when applying dynamometric techniques, one must pay careful attention to proper stabilization and have knowledge of typical SCI compensatory patterns, such as shoulder external rotation during attempts at elbow extension and wrist extension during attempts at finger flexion. Hand-held dynamometry is limited in acute clinical trials due to its inability to measure changes in the weakest muscles, where the most potential for change exists, but may be useful for stronger muscles against gravity.

\section{ASSESSMENT OF HAND FUNCTION}

Several generic tests of hand function, most notably the Jebsen Test of Hand Function [56], have been used for measuring the hand function of persons with tetraplegia $[7,10]$. Van Tuijl describes and applies many generic hand-function tests [10]. Stroh-Wuolle et al. [8-9], Mulcahey et al. [57-59], and Bryden et al. [11] describe the limitations of generic hand-function tests when applied to persons with tetraplegia and, as a direct result of these limitations, advise against their use in SCI clinical practice and research studies. 
Several evaluation tools have been developed specifically for use with persons with cervical (C)-level SCI, and although they may claim to be measures of hand function, many are actually multidimensional assessments of ADL. For example, in contrast to the Jebsen Test of Hand Function that measures grasp and release and object manipulation, the Sollerman Hand Function Test evaluates $20 \mathrm{ADL}$ that require the most common types of gripping strategies [60]. Execution of ADL requires factors beyond hand function, and thus these other factors confound the measurement of hand function. Likewise, Marino's Capabilities of the Upper Extremity (CUE) instrument [61] and Fattal's Motor Capacity Scale [62] may indirectly measure hand function but focus largely on the execution of tasks that require body movements and stability beyond hand grasp and release. The CUE [61] is a 17-item questionnaire in which patients rate on a 7-point ordinal scale their ability to perform functional tasks with their arms. The CUE separates proximal arm function from hand function and effectively measures outcomes after surgery for improving UL function [61]; Marino is currently developing and refining the CUE for use as an observational measure rather than patient report. The Motor Capacity Scale evaluates motor capacities that correspond to functional activities typical of persons with SCI regardless of contextual and environmental influences. The Tetraplegia Hand Activity Questionnaire (THAQ) is another diseasespecific measure that evaluates UL function in SCI [63]. The THAQ was developed with the Delphi Method, which resulted in the inclusion of arm-hand activities that are meaningful to SCI. Clinical applications of the THAQ have not been reported.

The Sollerman Hand Function Test, CUE, Motor Capacity Scale, and THAQ are well-designed and evaluate meaningful tasks for people with tetraplegia; at least one or a battery of several of these tools should be used in clinical practice to build evidence for interventions. These tools may also be useful in clinical trials and intervention studies with persons with chronic tetraplegia. Their application, however, in acute clinical trials may be limited.

The only measurement tool that was developed specifically for measurement of hand function (open and close, grasp and release) in persons with tetraplegia and that has addressed the limitations of generic hand tests is the Grasp and Release Test (GRT) [9]. The GRT measures three variables: pinch strength, grasp strength, and hand function. For the assessment of hand function, the GRT requires the person to unilaterally acquire and then carry and release five objects of varying weight and size; the "carrying" of objects does not require midline crossing and therefore eliminates proximal contributions to function. A sixth object, the fork, is used for simulating pinching of a fork handle and stabbing of food. The number of objects successfully manipulated and the number of repetitions achieved in a 30-second trial are scored. Wuolle et al. first reported on the psychometrics of the GRT [9], which were further established by Mulcahey et al. [64]. In Mulcahey et al.'s study, intraclass correlation coefficients were high for repeated GRT test measures; the GRT scores were stable over time for chronic stable hand-function measurement and were sensitive to changes in hand function via FES and tendon transfers. Clinically, the GRT has been an effective outcome measure for intervention studies of FES and tendon transfers [58,64-69]. Like all tests of hand function, the GRT requires the person to sit upright in the wheelchair; this prerequisite limits GRT use in clinical trials involving persons with acute SCI who are not medically stable for sitting. Another limitation of the GRT may be that its original intent was the evaluation of changes caused by FES lateral and palmar grasp; therefore, it may be insensitive to other grasp patterns and/or injury levels that typically do not use current FES systems (e.g., high and low cervical SCI).

\section{ELECTRODIAGNOSTICS}

Electrophysiological measures commonly performed for individuals with tetraplegia include stimulated muscle testing, strength-duration (SD) testing, evoked-potential testing, nerve conduction velocity (NCV) testing, and needle and dynamic electromyography (EMG) testing. The utility of each measure, site of injury, clinical presentation, and reason for referral are considerations in the choice of electrophysiological test [70-72].

Stimulated muscle testing is the surface application of electrical stimulation to a muscle or nerve for assessment of the lower motor neuron (LMN) muscle response [73]. The examiner determines the extent of axonal involvement rostral and caudal to the zone of injury by assessing the quality of the LMN muscle response [73]. Responses to stimulated muscle testing have been 
recorded with the interpretations defined from conventional manual muscle-testing scales [73]. For investigators interested in detecting subtler changes in strength over time, dynamometric testing is recommended [51].

SD testing involves the application of direct current to a muscle or nerve through a surface probe for assessment of normal, partial, or absent innervation [71-72]. Plotting a curve of stimulus intensity to pulse duration (called the SD Curve) or obtaining an intensity and duration value with set instrument parameters (called Rheobase-Chronaxie) can assess the extent of innervation [7172]. The SD Curve graphically represents the quality of innervation, while the Rheobase-Chronaxie provides a specific intensity and duration value for repeat comparison [71-72]. The magnitude of axonal involvement measured with either SD testing or stimulated muscle testing does not directly predict functional ability or performance [71-72].

NCV testing is a form of evoked-potential testing; electrical stimulus is delivered to the nerve while a sensory, motor, or sympathetic response is simultaneously recorded [70]. This procedure is routinely performed for determining the location and magnitude of LMN involvement [70]. EMG testing is most commonly performed with a monopolar or concentric needle to assess muscle during insertion, rest, and voluntary recruitment [70]. When NCV testing is performed in conjunction with needle EMG testing, the clinician gains added information on the nature (axonal and/or demyelinating condition, myogenic vs neurogenic) and magnitude of injury (extent of recruitment) [70].

Dynamic EMG analysis entails the application of surface or fine-wire recording electrodes for examination of electrical activity of muscle during passive or active movement [71-72]. Dynamic EMG can be used for examining the frequency components of muscle and analyze muscle contraction characteristics during select conditions or functionally meaningful tasks [71-72]. EMG signaling is often synchronized with movement data through the use of reflective markers or electrogoniometric measurement [71-72].

Previous investigators reported on electrophysiological changes that occur to peripheral and central structures following primary spinal insult [73-81]. While electrophysiological testing has been performed in SCI for predicting injury [74-75,82-85], examining the nature of neurological injury [71-72,86-92], monitoring the integrity of spinal conduction [77,93-94], and assessing for concomitant or secondary neurological conditions [9599], its role as a method of evaluating the impact of various interventions [65-66,81-82,100-106] is the concern of this article.

Electrophysiological testing has in many cases assessed for interventions appropriate for patients with SCI [65-66,81]. Stimulated muscle testing has assessed the functional integrity of the LMN for functionally stimulated interventions [65-66,73]. While intact stimulated responses within the C7-T1 muscles are critical for successful, minimally invasive hand implantation, the clinician must consider the extent of proximal volitional control for functional use of the limb [65-66,73]. While individuals with C5- or C6-level SCI may have the option of implanted hand function, the challenge today for individuals with C4-level tetraplegia is the lack of volitional or stimulated shoulder or elbow function [73]. A recent investigation at our facility restored either volitional or stimulated LMN function in nonfunctional and significantly denervated C5 muscles. Viable donor nerves with either volitional or stimulated function were transferred into C5 muscles with significant LMN and functional loss. While this investigation demonstrated neurological recovery in 8 of 12 procedures at 18 months follow-up, future work is needed for restoration of functional recovery.

The concept of activating a "central spinal generator" during activity-based regimens such as cycling and partial-weight-support treadmill training has been proposed [43]. Many investigators used the $\mathrm{H}$ reflex as the primary neurophysiological measure for monitoring changes in spinal modulation with the introduction of various activity-based regimens [103-105]. The functional significance of changes in the H-reflex response to functional ambulation in humans has not been demonstrated [43,103-105]. A recent investigation reported on the association between H-reflex habituation and reduced spasticity in patients following passive cycling [106]. Further work is needed for the full development of $\mathrm{H}$ reflex testing as a reliable evaluation of interventions targeted at the central spinal generator.

Kinesiological EMG may be another valuable electrodiagnostic tool for UL assessment in persons with tetraplegia. Kinesiological EMG has examined differences in shoulder recruitment during simulated wheelchair propulsion [100]. Persons with tetraplegia demonstrated greater vertical shoulder forces coupled with reduced shoulder-depressor strength compared with persons with 
paraplegia [101]. Persons with tetraplegia rely on proportionally greater anterior deltoid activity when attempting to perform a pressure-relief maneuver [97,107-108]. This finding contrasted with persons with typical shoulder muscular innervation who relied on the pectoralis major, latissimus dorsi, and triceps [98].

The pattern of kinesiological EMG muscle activity following C6-level SCI was analyzed during four common ADL and a select weight-lifting activity [101]. Subjects with tetraplegia required greater relative EMG activation for a $2 \mathrm{~kg}$ weight, while little difference was found versus controls for each of the four ADL [101]. When subjects attempted to increase their shoulder elevation beyond their normal workspace, a relative increase in EMG activity (anterior deltoid, supraspinatus, infraspinatus, and scapular muscles) was found versus controls [101]. These studies suggest that kinesiological EMG may potentially evaluate the small but clinically important differences in muscle activity in SCI. To date, we are unaware of a kinesiological investigation in tetraplegia that has examined differences in muscle activation patterns in relation to performance on the GRT, Sollerman Hand Function Test, CUE, Motor Capacity Scale, or THAQ.

\section{CONSIDERATIONS FOR CLINICAL TRIALS AND OUTCOME STUDIES}

The UL function of persons with tetraplegia plays a pivotal role in the degree to which they can spontaneously and effortlessly participating in self-selected activities; this basic premise has been a primary assumption in the development of SCI-specific hand-function tests. Relatively speaking, however, little work has focused on the development and use of a universally accepted method of measuring the UL of persons with tetraplegia across the care (acute to chronic) and age (pediatric to geriatric) continuums. Lack of a UL assessment tool is a major barrier to research on and evidence-building for UL interventions in SCI [5].

Clinical trials involving acute interventions enroll persons who may not be medically stable and are therefore unable to sit; hand-function tests require sitting endurance. Therefore, hand-function tests are inappropriate for clinical trials during the acute phase of SCI. However, measures of strength and perhaps electrodiagnostics can be used in acute clinical trials. Strength-testing all
UL muscles and classifying the UL according to both the ISCSCI and ICSHT are recommended. ICSHT is more sensitive to the UL in tetraplegia and has greater clinical significance than the ISCSCI. Electrodiagnostic measures may provide a method of monitoring neurological changes over time and may be an important adjunct to manual strength testing; further development and validation of these techniques are warranted.

Once a person with tetraplegia is able to sit, the GRT is a good tool for evaluating hand function and should be considered a primary measurement tool in clinical trials involving persons outside the acute-care phase and for outcome studies of UL orthoses, FES, and reconstructive procedures. With the exception of the Freehand clinical trial [68], the usefulness of the GRT in clinical trials is unexplored. While the GRT indirectly measures hand function, the CUE provides a functional perspective that, combined with the GRT, provides information on overall UL function. In the future, an observational CUE will be available that may strengthen this measure's utility. While measures of ADL were not discussed, they, too, indirectly measure UL function. Last, computer-adaptive testing platforms likely will provide precision and meaningful outcomes data in the near future [109].

Ideally, a measurement scheme based on the International Classification of Functioning, Disability, and Health model [110] as described by Sinnott et al. [111] would contribute greatly to the understanding of the impact of UL recovery and interventions on impairment, activity, and participation.

\section{CONCLUSIONS}

This article briefly discussed several measurement tools for evaluating the UL of persons with tetraplegia. While muscle strength testing and electrodiagnostics can be useful measures in acute clinical trials and outcomes studies, standardized measures of hand function are difficult because they require a sitting balance and endurance that many people with acute tetraplegia simply do not have. Acute trials should incorporate the ICSHT motor and sensory exam and classification system in addition to the ISCSCI and should consider the role of electrodiagnostics. The GRT, coupled with other indirect measures of UL function, is recommended for clinical trials involving persons with chronic SCI. Obviously, much work remains in the development, validation, and deployment 
of an assessment of the UL in persons with SCI that will be useful for clinical trials and outcomes research.

\section{ACKNOWLEDGMENTS}

This material is the result of work supported with resources and the use of facilities at the Shriners Hospitals for Children, Philadelphia, Pennsylvania.

The authors have declared that no competing interests exist.

\section{REFERENCES}

1. McDowell CL, Moberg EA, Smith AG. International conference on surgical rehabilitation of the upper limb in tetraplegia. J Hand Surg [Am]. 1979;4(4):387-90.

[PMID: 38273]

2. McDowell CL, Moberg EA, House JH. Proceedings: Second international conference on surgical rehabilitation of the upper limb in tetraplegia. J Hand Surg [Am]. 1986;11: 604-8.

3. Moberg EA, McDowell CL, House JH. Third international conference on surgical rehabilitation of the upper limb in tetraplegia (quadriplegia). J Hand Surg [Am]. 1989; 14(6):1064-6. [PMID: 2584649]

4. Hentz VR, House JH, McDowell CL, Moberg EA. Rehabilitation and surgical reconstruction of the upper limb in tetraplegia: An update. J Hand Surg [Am]. 1992;17(5): 964-67. [PMID: 1401816]

5. Landi A, Mulcahey MJ, Caserta G, Della Rosa N. Tetraplegia: Update on assessment. Hand Clin. 2002;18(3): 377-89. [PMID: 12474590]

6. Leclercq C, editor. Hand Clinics: The tetraplegic upper limb. Philadelphia (PA): W. B. Saunders Company; 2002.

7. Hentz VR, Leclercq C. Surgical rehabilitation of the upper limb in tetraplegia. Philadelphia (PA): W. B. Saunders Company; 2002.

8. Stroh-Wuolle K, Van Doren C. Common object test: A functional assessment for quadriplegic patients using an FNS hand system. In: Proceedings of RESNA Annual Conference; 1989 Jun 25-30; New Orleans, LA. Washington (DC): RESNA; 1989. P.387-88.

9. Wuolle KS, Van Doren CL, Thrope GB, Keith MW, Peckham PH. Development of a quantitative hand grasp and release test for patients with tetraplegia using a hand neuroprosthesis. J Hand Surg [Am]. 1994;19(2):209-18. [PMID: 8201183]
10. Van Tuijl JH, Janssen-Potten YJ, Seelen HA. Evaluation of upper extremity motor function tests in tetraplegics. Spinal Cord. 2002;40(2):51-64. [PMID: 11930877]

11. Bryden AM, Sinnott AK, Mulcahey MJ. Innovative strategies for improving upper extremity function in tetraplegia and considerations in measuring functional outcomes. Top Spinal Cord Inj Rehabil. 2005;10(4):75-93.

12. Watson AH, Kanny EM, White DM, Anson DK. Use of standardized activities of daily living scales in spinal cord injury and disease services. Am J Occup Ther. 1995;49(3): 229-34. [PMID: 7741156]

13. Marino RJ, Goin JE. Development of a short-form Quadriplegia Index of Function scale. Spinal Cord. 1999;37(4): 289-96. [PMID: 10338351]

14. Marino RJ, Huang M, Knight P, Herbison GJ, Ditunno JF Jr, Segal M. Assessing selfcare status in quadriplegia: Comparison of the quadriplegia index of function (QIF) and the functional independence measure (FIM). Paraplegia. 1993;31(4):225-33. [PMID: 8493037]

15. Fujiwara T, Hara Y, Akaboshi K, Chino N. Relationship between shoulder muscle strength and functional independence measure (FIM) score among C6 tetraplegics. Spinal Cord. 1999;37(1):58-61. [PMID: 10025698]

16. Deutsch A, Braun S, Granger CV. The functional independence measure (FIM Instrument). J Rehabil Outcomes Measures. 1997;1(2):67-71.

17. Kucukdeveci AA, Yavuzer G, Elhan AH, Sonel B, Tennant A. Adaptation of the Functional Independence Measure for use in Turkey. Clin Rehabil. 2001;15(3): 311-19. [PMID: 11386402]

18. Mahoney FI, Barthel DW. Functional evaluation: The Barthel Index. Md State Med J. 1965;14:61-65. [PMID: 14258950]

19. Gresham GE, Labi MLC, Dittmar SS, Hicks JT, Joyce SZ, Stehlik MA. The Quadriplegia Index of Function (QIF): Sensitivity and reliability demonstrated in a study of thirty quadriplegic patients. Paraplegia. 1986;24(1):38-44. [PMID: 3960588]

20. Catz A, Itzkovich M, Agranov E, Ring H, Tamir A. SCIM-Spinal cord independence measure: A new disability scale for patients with spinal cord lesions. Spinal Cord. 1997;35(12):850-56. [PMID: 9429264]

21. Klein RM, Bell B. Self care skills: Behavioral measurement with Klein-Bell ADL scale. Arch Phys Med Rehabil. 1982;63(7):335-38. [PMID: 7092535]

22. American Spinal Injury Association. Standards for classification of spinal injured patients. Chicago (IL): American Spinal Injury Association; 1982.

23. American Spinal Injury Association. Standards for classification of spinal injured patients. Chicago (IL): American Spinal Injury Association; 1992. 
24. Marino RJ, Barros T, Biering-Sorensen F, Burns SP, Donovan WH, Graves DE, Haak M, Hudson LM, Priebe MM, ASIA Neurological Standards Committee 2002. International standards for neurological classification of spinal cord injury. J Spinal Cord Med. 2003;26(Suppl 1): S50-56. [PMID: 16296564]

25. American Spinal Injury Association. Reference manual for the international standards for neurological classification of spinal cord injury. Chicago (IL): American Spinal Injury Association; 2003.

26. Betz RR, Mulcahey MJ. The child with spinal cord injury. Rosemont (IL): American Academy of Orthopaedic Surgeons; 1996.

27. National Spinal Injury Statistical Center. The annual statistical report for the Shrine spinal cord injury units. Birmingham (AL): National Spinal Cord Injury Statistical Center; 2003.

28. Stover S, DeLisa J, Whiteneck G. Spinal cord injury: Clinical outcomes from the model systems. Gaithersburg (MD): Aspen; 1995.

29. Blaustein DM, Zafonte R, Thomas D, Herbison GJ, Ditunno JF. Predicting recovery of motor complete quadriplegic patients. 24 hour v 72 hour motor index scores. Am J Phys Med Rehabil. 1993;72(5):306-11.

[PMID: 8398023]

30. Brown PJ, Marino RJ, Herbison GJ, Ditunno JF. The 72hour examination as a predictor of recovery in motor complete quadriplegia. Arch Phys Med Rehabil. 1991;72(8): 546-48. [PMID: 2059130]

31. Lazar RB, Yarkony GM, Ortolano D, Heinemann AW, Perlow E, Lovell L, Meyer PR. Prediction of functional outcome by motor capability after spinal cord injury. Arch Phys Med Rehabil. 1989;70:819-22. [PMID: 2818153]

32. Mange KC, Ditunno JF, Herbison GJ, Jaweed MM. Recovery of strength at the zone of injury in motor complete and motor incomplete cervical spinal cord injured patients. Arch Phys Med Rehabil. 1990;71(8):562-65. [PMID: 2369290]

33. Maynard FM, Reynolds GG, Fountain S, Wilmont C, Hamilton R. Neurological prognosis after traumatic quadriplegia. J Neurosurg. 1979;50(5):611-16. [PMID: 430155]

34. Waters RL, Yakura JS, Adkins RH, Sie I. Recovery following complete paraplegia. Arch Phys Med Rehabil. 1992;73(9):784-89. [PMID: 1514883]

35. Waters RL, Adkins RH, Yakura JS, Sie I. Motor and sensory recovery following complete tetraplegia. Arch Phys Med Rehabil. 1993;74(3):242-47. [PMID: 8439249]

36. Curt A, Rodic B, Schurch B, Dietz V. Recovery of bladder function in patients with acute spinal cord injury: Significance of ASIA scores and somatosensory evoked potentials. Spinal Cord. 1997;35(6):368-73. [PMID: 9194259]
37. De la Barrera S, Barca-Buyo A, Montoto-Marques A, Ferreiro-Velasco E, Cidoncha-Dans $\mathrm{M}$, Rodriquez-Sotillo A. Spinal cord infarction: Prognosis and recovery in a series of 36 patients. Spinal Cord. 2001;39:520-25.

38. Cifu D, Steel R, Kreutzer J, Marwitz J, McKinley W, Wisor D. Age, outcome and rehabilitation costs after tetraplegia spinal cord injury. NeuroRehabilitation. 1999;12: 177-85.

39. Middleton JW, Truman G, Geraghty TJ. Neurological level effect on the discharge functional status of spinal cord injured persons after rehabilitation. Arch Phys Med Rehabil. 1998;79(11):1428-32. [PMID: 9821905]

40. Muslumanoglu L, Aki S, Ozturk Y, Soy D, Filiz M, Karan A, Berker E. Motor, sensory and functional recovery in patients with spinal cord lesions. Spinal Cord. 1997;35(6): 386-89. [PMID: 9194262]

41. Rogers JC, Figone JJ. Traumatic quadriplegia: Follow up study of self care skills. Arch Phys Med Rehabil. 1980; 61(7):316-21. [PMID: 7396683]

42. Bracken MB, Shephard MJ, Collins WF, Holford T, Young W, Baskin D, Eisenberg H, Flamm E, Leo-Summers L, Maroon J, Marshall L, Perot P, Piepmeirer J, Sonntag V, Wagner F, Wilberger J, Winn HR. A randomized, controlled trial of methylprednisolone or naloxone in the treatment of acute spinal-cord injury. Results of the Second National Acute Spinal Cord Injury Study. N Engl J Med. 1990; 332(2):1405-11. [PMID: 2278545]

43. McDonald JW, Becker D, Sadowsky CL, Jane JA Sr, Conturo TE, Schultz LM. Late recovery following spinal cord injury. Case report and review of the literature. J Neurosurg. 2002;97(2 Suppl):252-65. [PMID: 12296690]. Erratum in: J Neurosurg. 2002;97(3 Suppl):405-6.

44. Glenn WW, Phelps ML, Elefteriades JA, Dentz B, Hogan JF. Twenty years of experience in phrenic nerve stimulation to pace the diaphragm. Pacing Clin Electrophysiol. 1986;9(6 Pt 1):780-84. [PMID: 2432480]

45. Keith MW, Peckham PH, Thrope GB, Stroh KC, Smith B, Buckett JR, Kilgore KL, Jatich JW Implantable functional neuromuscular stimulation in the tetraplegic hand. J Hand Surg [Am]. 1989;14(3):524-30. [PMID: 2786897]

46. Sharkey PC, Halter JA, Nakajima K. Electrophrenic respiration in patients with high quadriplegia. Neurosurgery. 1989;24(4):529-35. [PMID: 2710297]

47. Stein RB, Belanger M, Wheeler G, Wieler M, Popovic DB, Prochazka A, Davis LA. Electrical systems for improving locomotion after spinal cord injury. An assessment. Arch Phys Med Rehabil. 1993;74(9):954-59. [PMID: 8379842]

48. Triolo RJ, Betz RR, Mulcahey MJ, Gardner ER. Application of functional neuromuscular stimulation to children with spinal cord injuries: Candidate selection for upper 
and lower extremity research. Paraplegia. 1994;32(12): 824-43. [PMID: 7708423]

49. Mulcahey MJ, Gaughan J, Betz RR, Johanson K. The International Standards for Neurological Classification of Spinal Cord Injury: Reliability of data when applied to children and youths. Spinal Cord. In press 2006. [PMID: 17016490]

50. Noreau L, Vachon J. Comparison of three methods to assess muscle strength in individuals with spinal cord injury. Spinal Cord. 1998;36(10):716-23. [PMID: 9800275]

51. Schwartz S, Cohen ME, Herbison GJ, Shah A. Relationship between two measures of upper extremity strength: Manual muscle test compared to hand-held myometry. Arch Phys Med Rehab. 1992;73(11):1063-68. [PMID: 1444773]

52. Herbison GJ, Isaac Z, Cohen ME, Ditunno J. Strength post-spinal cord injury: Myometer vs manual muscle test. Spinal Cord. 1996;34(9):543-48. [PMID: 8883189]

53. May LA, Burnham RS, Steadward RD. Assessment of isokinetic and hand-held dynamometer measures of rotator strength among individuals with spinal cord injury. Arch Phys Med Rehabil. 1997;78(3):251-55. [PMID: 9084345]

54. Burns SP, Breuninger A, Kaplan C, Marin H. Hand-held dynamometry in persons with tetraplegia: Comparison of make- versus break-testing techniques. Am J Phys Med Rehabil. 2005;84(1):22-29. [PMID: 15632485]

55. Fattal C, Thery JM, Micallef JP. Validation of the motor capacities scale: A specific evaluation of manual abilities in tetraplegics who undergo functional surgery of the upper limbs [in French]. Ann Readapt Med Phys. 2004; 47(8):537-45. [PMID: 15465158]

56. Jebsen RH, Taylor N, Trieschmann RB, Trotter MJ, Howard LA. An objective and standardized test of hand function. Arch Phys Med Rehabil. 1969;50(6):311-19. [PMID: 5788487]

57. Mulcahey MJ. Rehabilitation and outcomes of upper extremity tendon transfer surgery. In: Betz RR, Mulcahey MJ, editors. The child with spinal cord injury. Rosemont (IL): American Academy of Orthopaedic Surgeons; 1996.

58. Mulcahey MJ, Betz RR, Smith BT, Weiss AA. A prospective evaluation of upper extremity tendon transfers in children with cervical spinal cord injury. J Pediatr Orthop. 1999;19(3):319-28. [PMID: 10344314]

59. Mulcahey MJ, Lutz C, Kozin SH, Betz RR. Prospective evaluation of biceps to triceps and deltoid to triceps for elbow extension in tetraplegia. J Hand Surgery [Am]. 2003;28(6):964-71. [PMID: 14642512]

60. Sollerman C, Ejeskar A. Sollerman hand function test. A standardised method and its use in tetraplegic patients. Scand J Plast Reconstr Surg Surg Hand Surg. 1995; 29(2):167-76. [PMID: 7569815]

61. Marino, RJ, Shea JA, Stineman MG. The Capabilities of Upper Extremity instrument: reliability and validity of a measure of functional limitation in tetraplegia. Arch Phys Med Rehabil. 1998(12);79:1512-21. [PMID: 9862292]

62. Fattal C. Motor capacities of upper limbs in tetraplegics: A new scale for assessment of the results of functional surgery on upper limbs. Spinal Cord. 2004;42(2):80-90. [PMID: 14765140]

63. Land NE, Odding E, Duivenvoorden HJ, Bergen MP, Stam HJ. Tetraplegia hand activity questionnaire (THAQ): The development, assessment of arm-handfunction-related activities in teraplegic patients with spinal cord injury. Spinal Cord. 2004;42(5):294-301. [PMID: 14993892]

64. Mulcahey MJ, Smith BT, Betz RR. Psychometric rigor of the Grasp and Release Test for measuring functional limitation of persons with tetraplegia: A preliminary analysis. J Spinal Cord Med. 2004;27(1):41-46. [PMID: 15156936]

65. Mulcahey MJ, Betz RR, Smith, BT, Weiss AA, Davis SE. Implanted functional electrical stimulation hand system in adolescents with spinal injuries: An evaluation. Arch Phys Med Rehabil. 1997;78(6):597-607. [PMID: 9196467]

66. Mulcahey MJ, Betz RR, Kozin SH, Smith BT, Hutchinson D, Lutz C. Implantation of the Freehand System during initial rehabilitation using minimally invasive techniques. Spinal Cord. 2004;42(3):146-55. [PMID: 15001979]

67. Smith BT, Mulcahey MJ, Betz RR. Quantitative comparison of grasp and release abilities with and without functional neuromuscular stimulation in adolescents with tetraplegia. Paraplegia. 1996;34(1):16-23. [PMID: 8848318]

68. Peckham PH, Keith MW, Kilgore KL, Grill JH, Wuolle KS, Thrope GB, Gorman P, Hobby J, Mulcahey MJ, Carroll S, Hentz VR, Wiegner A, Implantable Neuroprosthesis Research Group. Efficacy of an implanted neuroprosthesis for restoring hand function in tetraplegia: A multicenter study. Arch Phys Med Rehabil. 2001;82(10):1380-88. [PMID: 11588741]

69. Kilgore KL, Peckham HP, Keith MW, Thrope GB, Wuolle KS, Bryden AM, Hart RL. An implanted upperextremity neuroprosthesis. Follow-up of five patients. J Bone Joint Surg Am. 1997;79(4):533-41. [PMID: 9111397]

70. Dumitru D. Electrodiagnostic medicine. Philadelphia (PA): Hanley and Belfus Medical Publications; 1995.

71. Nelson RM, Hayes Kw, Currier DP. Clinical electrotherapy, 3d ed. Standford (CT): Appleton \& Lange; 1987.

72. Robinson AJ, Synder-Mackler L. Clinical electrophysiology. Baltimore (MD): Lippincott Williams \& Wilkins; 1989.

73. Mulcahey MJ, Smith BT, Betz RR. Evaluation of the lower motor neuron integrity of upper extremity muscles in high level spinal cord injury. Spinal Cord. 1999;37(8): 585-91. [PMID: 10455536]

74. Curt A. Neurological diagnosis and prognosis: Significance of neurophysiological findings in traumatic spinal 
cord lesions [in German]. Schweiz Med Wochenschr. 2000;130(22):801-10. [PMID: 10893751]

75. Curt A, Dietz V. Traumatic cervical spinal cord injury: Relation between somatosensory evoked potentials, neurological deficit, and hand function. Arch Phys Med Rehabil. 1996;77(1):48-53. [PMID: 8554473]

76. Thomas CK, Zaidner EY, Calancie B, Broton JG, BiglandRitchie BR. Muscle weakness, paralysis, and atrophy after human cervical spinal cord injury. Exp Neurol. 1997; 148(2):414-23. [PMID: 9417821]

77. Cheliout-Heraut F, Loubert G, Masri-Zada T, Aubrun F, Pasteyer J. Evaluation of early motor and sensory evoked potentials in cervical spinal cord injury. Neurophysiol Clin. 1998;28(1):39-55. [PMID: 9562998]

78. Burnham R, Martin T, Stein R, Bell G, MacLean I, Steadward R. Skeletal muscle fibre type transformation following spinal cord injury. Spinal Cord. 1997;35(2):86-91. [PMID: 9044514$]$

79. Gaviria M, Ohanna F. Variability of the fatigue response of paralyzed skeletal muscle in relation to the time after spinal cord injury: Mechanical and electrophysiological characteristics. Eur J Appl Physiol Occup Physiol. 1999;80(2):145-53. [PMID: 10408326]

80. Shields RK. Muscular, skeletal, and neural adaptations following spinal cord injury. J Orthop Sports Phys Ther. 2002;32(2):65-74. [PMID: 11838582]

81. Hunter J, Ashby P. Secondary changes in segmental neurons below a spinal cord lesion in man. Arch Phys Med Rehabil. 1984;65(11):702-5. [PMID: 6497617]

82. Louis AA, Gupta P, Perkash I. Localization of sensory levels in traumatic quadriplegia by segmental somatosensory evoked potentials. Electroencephalogr Clin Neurophys. 1985;62(4):313-16. [PMID: 2408877]

83. Hayes KC, Wolfe DL, Hsieh JT, Potter PJ, Krassioukov A, Durham CE. Clinical and electrophysiologic correlates of quantitative sensory testing in patients with incomplete spinal cord injury. Arch Phys Med Rehabil. 2002;83(11): 1612-19. [PMID: 12422334]

84. Curt A, Keck ME, Dietz V. Functional outcomes following spinal cord injury: Significance of motor-evoked potentials and ASIA scores. Arch Phys Med Rehabil. 1998;79(1): 81-86. [PMID: 9440423]

85. Pierlovisi-Lavaivre M, De Bisschop G, Brant A, ChapuisDucoffre MF, Bence Y, Millet Y. Prognostic value of early somatosensory evoked potentials in the presence of traumatic lesion of the spinal cord [in French]. Rev Electroencephalogr Neurophysiol Clin. 1985;15(1):77-83. [PMID: 4048613]

86. McDonald WI. Mechanisms of functional loss and recovery in spinal cord damage. Ciba Found Symp. 1975;34: 23-33. [PMID: 177252]
87. Waxman SG. Demyelination in spinal cord injury and multiple sclerosis: What can we do to enhance functional recovery. J Neurotrauma. 1992;9(Suppl 1):S105-17. [PMID: 1588601]

88. Waxman SG. Demyelination in spinal cord injury. J Neurol Sci. 1989;91(1-2):1-14. [PMID: 2664092]

89. Smith KJ, McDonald WI. Spontaneous and evoked electrical discharges from a central demyelinating lesion. J Neurol Sci. 1982;55(1):39-47. [PMID: 6286890]

90. Campbell JW, Herbison GJ, Chen YT, Jaweed MM, Gussner CG. Spontaneous electromyographic potentials in chronic spinal cord injured patients: Relation to spasticity and length of nerve. Arch Phys Med Rehabil. 1991; 72(1):23-27. [PMID: 1985619]

91. Berman SA, Young RR, Sarkarati M, Shefner JM. Injury zone denervation in traumatic quadriplegia in humans. Muscle Nerve. 1996;19(6):701-6. [PMID: 8609919]

92. Kirshblum S, Lim S, Garstang S, Millis S. Electrodiagnostic changes of the lower limbs in subjects with chronic complete cervical spinal cord injury. Arch Phys Med Rehabil. 2001;82(5):604-7. [PMID: 11346835]

93. Epstein NE, Danto J, Nardi D. Evaluation of intraoperative somatosensory-evoked potential monitoring during 100 cervical operations. Spine. 1993;18(6):737-47. [PMID: 8516704]

94. Bose B, Sestokas AK, Schwartz DM. Neurophysiological monitoring of spinal cord function during instrumented anterior cervical fusion. Spine. 2004;4(2):202-7. [PMID: 15016399]

95. Stefaniwsky L, Bilowit DS, Prasad SS. Reduced motor conduction velocity of the ulnar nerve in spinal cord injured patients. Paraplegia. 1980;18(1):21-24. [PMID: 7375123]

96. Bursell JP, Little JW, Stiens SA. Electrodiagnosis in spinal cord injured persons with new weakness or sensory loss: Central and peripheral etiologies. Arch Phys Med Rehabil. 1999;80(8):904-9. [PMID: 10453766]

97. Nemchausky BA, Ubilluz RM. Upper extremity neuropathies in patients with spinal cord injuries. J Spinal Cord Med. 1995;18(2):95-97. [PMID: 7640979]

98. Burnham RS, Steadward RD. Upper extremity peripheral nerve entrapments among wheelchair athletes: Prevalence, location, and risk factors. Arch Phys Med Rehabil. 1994;75(5):519-24. [PMID: 8185443$]$

99. Goodman CM, Steadman AK, Meade RA, Bodenheimer C, Thornby J, Netscher DT. Comparison of carpal canal pressure in paraplegic and nonparaplegic subjects: Clinical implications. Plast Reconstr Surg. 2001;107(6):146471; discussion 1472. [PMID: 11335819]

100. Mulroy SJ, Farrokhi S, Newsam CJ, Perry J. Effects of spinal cord injury level on the activity of shoulder muscles during wheelchair propulsion: An electromyographic 
study. Arch Phys Med Rehabil. 2004;85(6):925-34. [PMID: 15179646]

101. Kulig K, Newsam CJ, Mulroy SJ, Rao SS, Gronley JK, Bontrager EL, Perry J. The effect of level of spinal cord injury on shoulder joint kinetics during manual wheelchair propulsion. Clin Biomech (Bristol, Avon). 2001; 16(9):744-51. [PMID: 11714551]

102. Gronley JK, Newsam CJ, Mulroy SJ, Rao SS, Perry J, Helm M. Electromyographic and kinematic analysis of the shoulder during four activities of daily living in men with C6 tetraplegia. J Rehabil Res Dev. 2000;37(4):42332. [PMID: 11028698$]$

103. Fung J, Barbeau H. Effects of conditioning cutaneomuscular stimulation on the soleus H-reflex in normal and spastic paretic subjects during walking and standing. J Neurophysiol. 1994;72(5):2090-2104. [PMID: 7884446$]$

104. Trimble MH, Kukulka CG, Behrman AL. The effect of treadmill gait training on low-frequency depression of the soleus H-reflex: Comparison of a spinal cord injured man to normal subjects. Neurosci Lett. 1998;246(3):186-88. [PMID: 9792623]

105. Trimble MH, Behrman AL, Flynn SM, Thigpen MT, Thompson FJ. Acute effects of locomotor training on overground walking speed and H-reflex modulation in individuals with incomplete spinal cord injury. J Spinal Cord Med. 2001;24(2):74-80. [PMID: 11587422]

106. Kiser TS, Reese NB, Maresh T, Hearn S, Yates C, Skinner RD, Pait TG, Garcia-Rill E. Use of a motorized bicy- cle exercise trainer to normalize frequency-dependent habituation of the H-reflex in spinal cord injury. J Spinal Cord Med. 2005;28(3):241-45. [PMID: 16048142]

107. Van Drongelen S, Van der Woude LH, Janssen TW, Angenot EL, Chadwick EK, Veeger DH. Glenohumeral contact forces and muscle forces evaluated in wheelchairrelated activities of daily living in able-bodied subjects versus subjects with paraplegia and tetraplegia. Arch Phys Med Rehabil. 2005;86(7):1434-40. [PMID: 16003677]

108. Gefen JY, Gelmann AS, Herbison GJ, Cohen ME, Schmidt RR. Use of shoulder flexors to achieve isometric elbow extension in C6 tetraplegic patients during weight shift. Spinal Cord. 1997;35(5):308-13. [PMID: 9160456]

109. Dijkers MP. A computer adaptive testing simulation applied to the FIM instrument motor component. Arch Phys Med Rehabil. 2003;84(3):384-93. [PMID: 12638107]

110. World Health Organization. International classification of functioning, disability and health. Geneva (Switzerland): World Health Organization; 2001.

111. Sinnott KA, Dunn JA, Rothwell AG. Use of the ICF conceptual framework to interpret hand function outcomes following tendon transfers for tetraplegia. Spinal Cord. 2004;42(7):396-400. [PMID: 15111992]

Submitted for publication October 28, 2005. Accepted in revised form February 23, 2006. 